\title{
Fluorapatite-fluid alteration: REE mobility and its implications for apatite as an exploration tool
}

\author{
J. CALEB CHAPPELL ${ }^{1}$, ALEXANDER GYSI ${ }^{2}$, THOMAS \\ MONECKE $^{1}$ AND ZHAOSHAN CHANG ${ }^{1}$ \\ ${ }^{1}$ Colorado School of Mines \\ ${ }^{2}$ New Mexico Tech \\ Presenting Author: jcchappell@mymail.mines.edu
}

A series of experiments were carried out to assess rare-earth element partitioning between apatite and hydrothermal fluids, and to assess the potential for apatite alteration at lowtemperature hydrothermal conditions. Durango fluorapatite fragments were reacted with solutions at a $\mathrm{pH}$ between 2-4, with either perchloric or hydrochloric acid as the titrating agent, and at $150^{\circ} \mathrm{C}$ or $250^{\circ} \mathrm{C}$ for $\sim 9$ days. Most experimental solutions were also doped with $1 \mathrm{ppm}$ per rare earth, and between $0.5-5 \mathrm{wt} \%$ $\mathrm{NaCl}$. SEM-BSE imaging revealed REE-rich phases precipitated on all reacted fluorapatite grains in this study, except for the two controls which only interacted with pure water. Solution ICP-MS on the reacted solutions indicated all solutions which were doped with REEs were depleted in REEs compared to their starting concentrations. Lanthanum and cerium concentrations in reacted sample solution Ap150_5_REE were both measured at 40ppb, compared to the initial concentration of $1 \mathrm{ppm}$ or $1000 \mathrm{ppb}$. Semiquantitative X-ray energy dispersive spectroscopy (XEDS) analyses on the REE phases in Ap150_5_REE give average values $(n=3)$ of $\mathrm{Ce}=30.9 \% \quad \mathrm{La}=11.6 \% \quad \mathrm{Nd}=5.5 \% \quad \mathrm{Ca}=4.6 \%$ $\mathrm{P}=17.1 \% \mathrm{O}=30.2 \%$.

This result shows the strong preference for the solid phase for lanthanum and cerium under these hydrothermal conditions with fluorapatite present. In experiments with initial REE doping, overall REE concentrations in the reacted solution were lowest in experiments containing $5 \mathrm{wt} \% \mathrm{NaCl}$ compared to similar experiments which only contained $0.5 \mathrm{wt} \% \mathrm{NaCl}$ or no $\mathrm{NaCl}$. Experiments which contained $5 \mathrm{wt} \% \mathrm{NaCl}$ also revealed the most intense alteration in fluorapatite grains, reaching up to $100 \mathrm{um}$ into the crystal. These results reveal the potential for apatite alteration under low-temperature $\left(<300^{\circ} \mathrm{C}\right)$ hydrothermal conditions. The potential for apatite alteration at these conditions must be taken into account when using apatite as a fertility indicator or vector in an ore deposit setting. Before experiments were performed, a single crystal of Durango fluorapatite was cut so that two LA-ICP-MS transects could be collected when looking perpendicular and parallel to the c-axis of the crystal. These transects revealed significant variation in REE concentrations from the core to the rim, with lanthanum concentrations increasing from $3500 \mathrm{ppm}$ in the core to $5000 \mathrm{ppm}$ in the rim. 